\title{
Prognostic value of the extent of lymphadenectomy for esophageal cancer- specific survival among T1 patients
}

Yang Wang ${ }^{1}$, Xiangwei Zhang ${ }^{2}$, Xiufeng Zhang ${ }^{3}$, Jing Liu-Helmersson ${ }^{4}$, Lin Zhang ${ }^{2}$, Wen Xiao ${ }^{2}$, Yuanzhu Jiang ${ }^{2}$, Keke Liu ${ }^{5}$ and Shaowei Sang ${ }^{6,7,8^{*}}$

\begin{abstract}
Background: Clinically, there are no clear guidelines on the extent of lymphadenectomy in patients with T1 esophageal cancer. Studying the minimum number of lymph nodes for resection may increase cancer-specific survival.

Methods: Patients who underwent esophagectomy and lymphadenectomy at T1 stage were selected from the Surveillance, Epidemiology and End Results Program (United States, 1998-2014). Maximally selected rank and Cox proportional hazard models were used to examine three variables: the number of lymph nodes examined, the number of negative lymph nodes and the lymph node ratio.

Results: Approximately 18\% had lymph node metastases, where the median values were 10, 10 and 0 for the number of lymph nodes examined, the number of negative lymph nodes and the lymph node ratio, respectively. All three examined variables were statistically associated with cancer-specific survival probability. Dividing patients into two groups shows a clear difference in cancer-specific survival compared to four or five groups for all three variables: there was a $29 \%$ decrease in the risk of death with the number of lymph nodes examined $\geq 14$ vs $<14$ (hazard ratio 0.71, 95\% confidence interval: 0.57-0.89), a 35\% decrease in the risk of death with the number of negative lymph nodes $\geq 13$ vs < 13 (hazard ratio 0.65 , 95\% confidence interval: $0.52-0.81$ ), and an increase of 1.21 times in the risk of death (hazard ratio 2.21, 95\% confidence interval: 1.76-2.77) for the lymph node ratio $>0.05$ vs $\leq 0.05$.

Conclusions: The extent of lymph node dissection is associated with cancer-specific survival, and the minimum number of lymph nodes that need to be removed is 14. The number of negative lymph nodes and the lymph node ratio also have prognostic value after lymphadenectomy among $\mathrm{T} 1$ stage patients.
\end{abstract}

Keywords: Esophageal cancer, T1, Cancer-specific survival, Prognosis, Extent of lymphadenectomy, Cutoff value

\footnotetext{
* Correspondence: sangshaowei@sdu.edu.cn

${ }^{6}$ Clinical Epidemiology Unit, Qilu Hospital of Shandong University, 107 Wenhua Road, Lixia District, Jinan 250012, People's Republic of China

${ }^{7}$ Clinical Research Center of Shandong University, Jinan 250012, People's Republic of China

Full list of author information is available at the end of the article
}

(c) The Author(s). 2021 Open Access This article is licensed under a Creative Commons Attribution 4.0 International License, which permits use, sharing, adaptation, distribution and reproduction in any medium or format, as long as you give appropriate credit to the original author(s) and the source, provide a link to the Creative Commons licence, and indicate if changes were made. The images or other third party material in this article are included in the article's Creative Commons licence, unless indicated otherwise in a credit line to the material. If material is not included in the article's Creative Commons licence and your intended use is not permitted by statutory regulation or exceeds the permitted use, you will need to obtain permission directly from the copyright holder. To view a copy of this licence, visit http://creativecommons.org/licenses/by/4.0/ The Creative Commons Public Domain Dedication waiver (http://creativecommons.org/publicdomain/zero/1.0/) applies to the data made available in this article, unless otherwise stated in a credit line to the data. 


\section{Background}

The American Joint Committee on Cancer (AJCC) TNM Classification suggests that lymph node status is one of the most significant prognostic factors in esophageal cancer. For staging purposes, the National Comprehensive Cancer Network (NCCN) guidelines recommend that a minimum of 15 lymph nodes should be removed and examined [1]; however, for therapeutic purposes, the extent of lymphadenectomy remains under debate, especially in patients with $\mathrm{T} 1$ esophageal cancer.

Lymph node metastasis is a common mechanism of cancer progression in esophageal cancer. Lymph node metastases are thought to be very rare in patients with early esophageal cancer, but studies have shown that the prevalence of lymph node metastases in $\mathrm{T} 1$ patients ranges from $16.6 \%$ to nearly $40 \%$ depending on different histopathological characteristics [2-6]. Lymph node metastasis is known to influence the prognosis of esophageal cancer. Esophagectomy is the standard treatment for early stage patients, but surgeons still debate the prognosis of the extent of lymph node dissection [7-10], and the extent of lymph node dissection is still unclear in $\mathrm{T} 1$ patients.

The purpose of the study is to (1) investigate the prevalence of lymph node metastases; (2) explore the relationship between the extent of lymph node resection and long-term cancer-specific survival (CSS) in T1 patients after esophagectomy and lymphadenectomy; and (3) find the optimal or the minimum number of lymph nodes that need to be removed.

\section{Methods}

Our study is based on the U.S. data from the Surveillance, Epidemiology and End Results (SEER) Program database (https://seer.cancer.gov/data/). The SEER database collects cancer incidence data from populationbased cancer registries, which includes patient demographics, primary tumor site, tumor morphology, stage at diagnosis, and follow-up with patients for vital status. The ASCII text version of data from 1973 to 2014 (released in November 2016) was downloaded for this study. The SEER data are deidentified and publicly available. Therefore, the study is exempted from institutional ethical review board approval.

We identified all cases of first primary esophageal cancer (International Classification of Diseases for Oncology with tumor site codes 150-155, 158-159). Then, we selected patients diagnosed with esophageal adenocarcinoma (EAC) (SEER codes 8140-8389) or squamous cell carcinoma (ESCC) (SEER codes 8050-8089) between 1988 and 2014. Next, we narrowed the cases down to include only those patients who were treated with esophagectomy and lymph node dissection and survived more than 3 months after the operation. Other inclusion criteria were microscopic diagnostic confirmation, T1 stage and active follow-up (obtaining the outcome of patients after surgery at periodic intervals by contacting the patient, a physician, family member, or other informant). Tumors with distant metastasis were excluded.

Demographic, diagnostic and survival information was extracted, including sex, age at diagnosis, year of diagnosis, primary site, grade, histology, lymph nodes examined, positive lymph nodes, tumor size, cancer-specific death and survival time. The primary outcome of the cohort was the time from diagnosis to esophageal cancerspecific death. Cases with missing data were excluded from the study.

In the study, the number of lymph nodes examined (nLNE), the number of negative lymph nodes (nLNN) and the lymph node ratio (LNR = the number of positive lymph nodes/nLNE)] was used to define the extent of lymph node dissection. The statistical method, maximally selected rank statistics [11], was used to identify the optimal cutoff point for the three main variables: nLNE, nLNN and LNR. Then, we divided patients first into four or five subgroups for each of the three variables considering the corresponding optimal cutoff point and the sample size in each subgroup with the following values: 1$) \leq 4,5-8,9-13,14-20, \geq 21$ for nLNE; 2$) \leq 4,5-$ 8, 9-12, 13-20 and $\geq 21$ for $n L N N$; 3) 0, 0.01-0.05, $0.06-0.20$ and $\geq 0.21$ for LNR. The survival probability was calculated as a function of time for each of the subgroups. Then, the same patients were divided into two groups based on the subgroup value and the cutoff point indicated by the maximally selected rank statistics method to check the survival probability again. When the survival probability shows a clear difference between the two new groups, the optimal cutoff is found.

The statistical methods used for determining the cancer-specific survival (CSS) probability curve and the relationship between CSS and each of the main three variables are described here. The Kaplan-Meier method was used to estimate the esophageal CSS probability curve. Using the log-rank test, CSS probabilities between different subgroups were compared. The 5- and 10-year CSS probabilities, as well as the median follow-up time (the median observed survival time among all patients), were analyzed. Specifically, we used the multivariate Cox proportional cancer-specific hazard model to analyze the relationship between CSS and each of the three main variables after controlling for other secondary variables: tumor size, tumor grade, histology, year of diagnosis, and age at diagnosis. The effect size of risk factors was quantified by using a cancer-specific hazard ratio (HR) with 95\% confidence intervals (95\% CIs).

In addition, we performed sensitivity analysis to test the stability of the results by comparing hazard ratios including and excluding patients with tumor size $>20 \mathrm{~cm}$ 
and lymph nodes examined $>25$ (126 patients in total), because these values are extreme values for $\mathrm{T} 1$ patients, and we cannot determine the accuracy of these extreme values. All statistical calculations were conducted by using R software (version 3.4.0).

\section{Results}

The demographic and tumor characteristics of T1 patients We identified 1268 eligible patients with EAC or ESCC (Fig. 1). The demographic and tumor characteristics are presented in Table 1. Most patients were men (84.2\%), and the median age of all patients was 63 years. The histologic type is mainly adenocarcinoma (79.9\%). Approximately $18.0 \%$ are lymph node metastases ( $\mathrm{LN}+$ ), among which the median number of $\mathrm{LN}+$ is 1 . The prevalence of $\mathrm{LN}+$ in EAC and ESCC is 17.7 and $18.4 \%$, respectively. The median values of lymph nodes examined, negative lymph nodes and the LNR were 10, 10 and 0 , respectively.

\section{Esophageal cancer-specific survival of T1 patients}

The median follow-up time for these patients was 45 months (range, 4 to 258 months). There are 415 deaths resulting from esophageal cancer. The estimated 5- and 10-year CSS probabilities for all patients were 66.8 and $59.4 \%$, respectively.

\section{Lymph node metastasis and esophageal cancer-specific survival}

Figure 2 shows the CSS probability of esophageal cancer with and without lymph node metastasis (LN+ vs LN-). The estimated 5- and 10-year CSS probabilities for patients with lymph node metastasis were 39.8 and $31.5 \%$, respectively, while they were 72.7 and $65.5 \%$ for patients without lymph node metastasis. This difference was significant $(P<0.001)$.

\section{nLNE and esophageal cancer-specific survival}

Figure 3 shows the CSS probability of esophageal cancer for different nLNEs. Figure 3a shows that the difference in CSS probability among the subgroups with different nLNEs $(\leq 4,5-8,9-13,14-20$, and $\geq 21)$ was significant $(P<0.001)$. Generally, the CSS probability of patients with more lymph node resection was higher, except for the group with 9 to 13 lymph node resections. Figure $3 \mathrm{~b}$ shows the CSS probability in the two groups separated based on a cutoff value of 13 . The results indicate that the CSS probability of patients with $\geq 14$ lymph nodes examined was significantly better than that of patients with $<14$ lymph nodes examined $(P<0.001)$. The estimated 5- and 10-year CSS probabilities for patients with $<14$ lymph nodes examined were 63.0 and $55.5 \%$, respectively, compared with 74.0 and $67.2 \%$ for patients with $\geq 14$ lymph nodes examined.

Figure 4 shows the effect of nLNE on CSS probability after controlling for tumor size, tumor grade, histology, year of diagnosis, and age at diagnosis. Figure $4 \mathrm{a}$ corresponds to dividing the nLNE into five groups $(\leq 4,5-8$, $9-13,14-20$, and $\geq 21$ ), whereas Fig. $4 \mathrm{~b}$ corresponds to dividing the nLNE into two groups $(\geq 14$ and $<14)$. Figure 4 a shows that this main variable is statistically associated with CSS probability. The point estimation effects of nLNE among different groups are nonlinear, with the 9-13 group having the largest point estimation, although

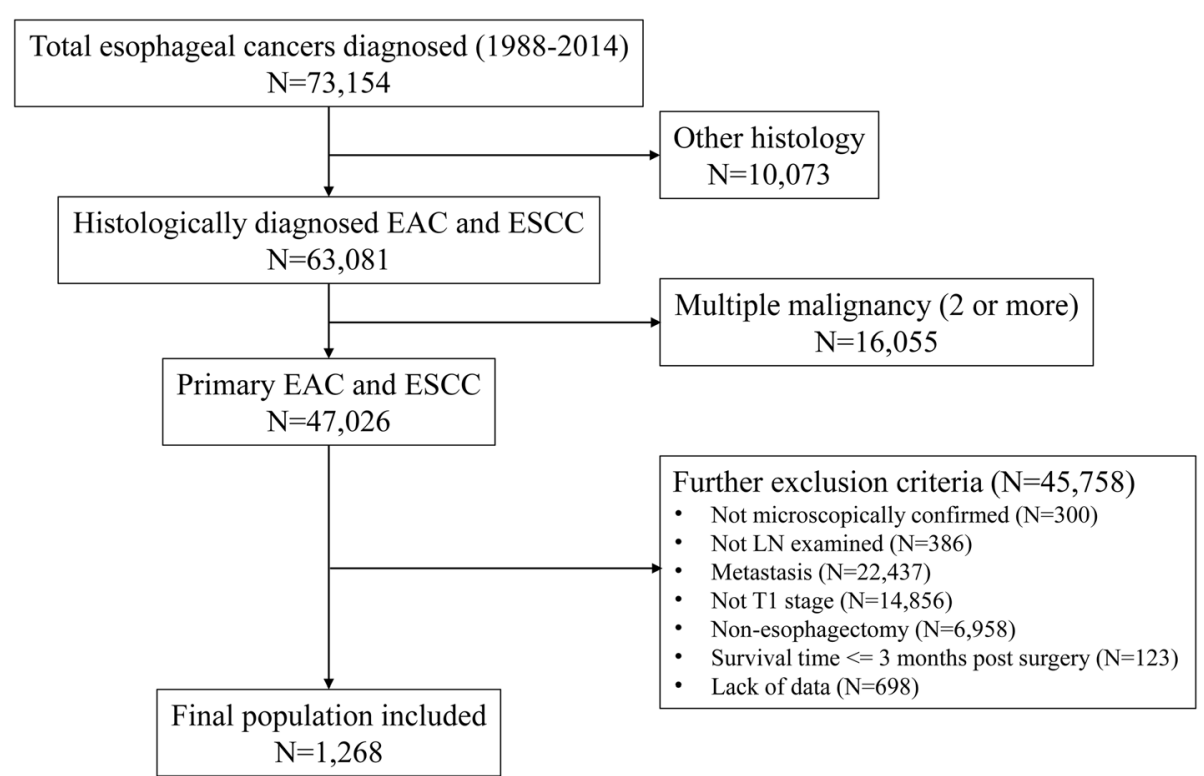

Fig. 1 Road map of the patients included 
Table 1 Characteristics of esophageal cancer patients undergoing resection

Variable

Age, years

Median, range

$<=68(n, \%)$

$>68(n, \%)$

Sex

Male $(n, \%)$

Female $(n, \%)$

Tumor size, $\mathrm{mm}$

Median, range

$<=25(n, \%)$

$>25(n, \%)$

\section{LNs status}

$\mathrm{LN}+, n(\%)$

$\mathrm{LN}-, n(\%)$

Number of LNs examined

Median, range

Category 1

$<=4(n, \%)$

5-8 $(n, \%)$

9-13 $(n, \%)$

$14-20(n, \%)$

$>=21(n, \%)$

Category 2

$<=13(n, \%)$

$>13(n, \%)$

Number of LNs negative

Median, range

Category 1

$<=4(n, \%)$

5-8 $(n, \%)$

9-12 $(n, \%)$

$13-20(n, \%)$

$>=21(n, \%)$

Category 2

$<=12(n, \%)$

$>12(n, \%)$

LNR

Median, range

Category 1

0

0.01-0.05

$0.06-0.20$

$>=0.21$

Category 2
All patients

$63(20,92)$

901 (71.1\%)

367 (28.9\%)

$1068(84.2 \%)$

$200(15.8 \%)$

$20(0,994)$

$763(60.2 \%)$

505 (39.8\%)

$226(17.8 \%)$

$1042(82.2 \%)$

$10(1,90)$

238 (18.8\%)

303 (23.9\%)

$268(21.1 \%)$

239 (18.8\%)

220 (17.4\%)

809 (63.8\%)

459 (36.2\%)

$10(0,90)$

262 (20.7\%)

308 (24.3\%)

$221(17.4 \%)$

270 (21.3\%)

207 (16.3\%)

791 (62.4\%)

477 (37.6\%)

$0(0,1)$

1042 (82.2\%)

$26(2.1 \%)$

115 (9.1\%)

85 (6.7\%) 
Table 1 Characteristics of esophageal cancer patients undergoing resection (Continued)

\begin{tabular}{lr}
\hline Variable & All patients \\
\hline$<=0.05(n, \%)$ & $1068(84.2 \%)$ \\
$>0.05(n, \%)$ & $200(15.8 \%)$ \\
Grade & $182(14.4 \%)$ \\
Well differentiated $(n, \%)$ & $613(48.3 \%)$ \\
Moderately differentiated $(n, \%)$ & $473(37.3 \%)$ \\
Poorly differentiated/Undifferentiated $(n, \%)$ & $1013(79.9 \%)$ \\
Histology & $255(20.1 \%)$ \\
$\quad$ Adenocarcinoma $(n, \%)$ & \\
Squamous cell carcinoma $(n, \%)$ & 1268 \\
Year of diagnosis & \\
$\quad 1988-2014$ & \\
\hline
\end{tabular}

the difference between the 5-8 group, 9-13 group or $14-20$ group and the $\leq 4$ group is insignificant. Figure $4 \mathrm{~b}$ shows that the cancer-specific death risk of patients with nLNE $\geq 14$ is decreased by $29 \%$ compared to those with nLNE $<14$ (HR 0.71, 95\% CI: 0.57-0.89).

\section{nLNN and esophageal cancer-specific survival}

Figure 5 shows the CSS probability of esophageal cancer for different nLNNs. Figure $5 \mathrm{a}$ shows that the difference in CSS probability among the subgroups with different nLNNs $(\leq 4,5-8,9-12,13-20$, and $\geq$ $21)$ was significant $(P<0.001)$. Similar to Fig. $4 a$, generally the more negative lymph nodes there were, the higher the CSS probability for patients, except for the group with 9 to 12 negative lymph nodes. Figure 5b shows the CSS probability in two groups separated based on a cutoff value of 12 . The results indicate that the CSS probability of patients with $\geq 13$ negative

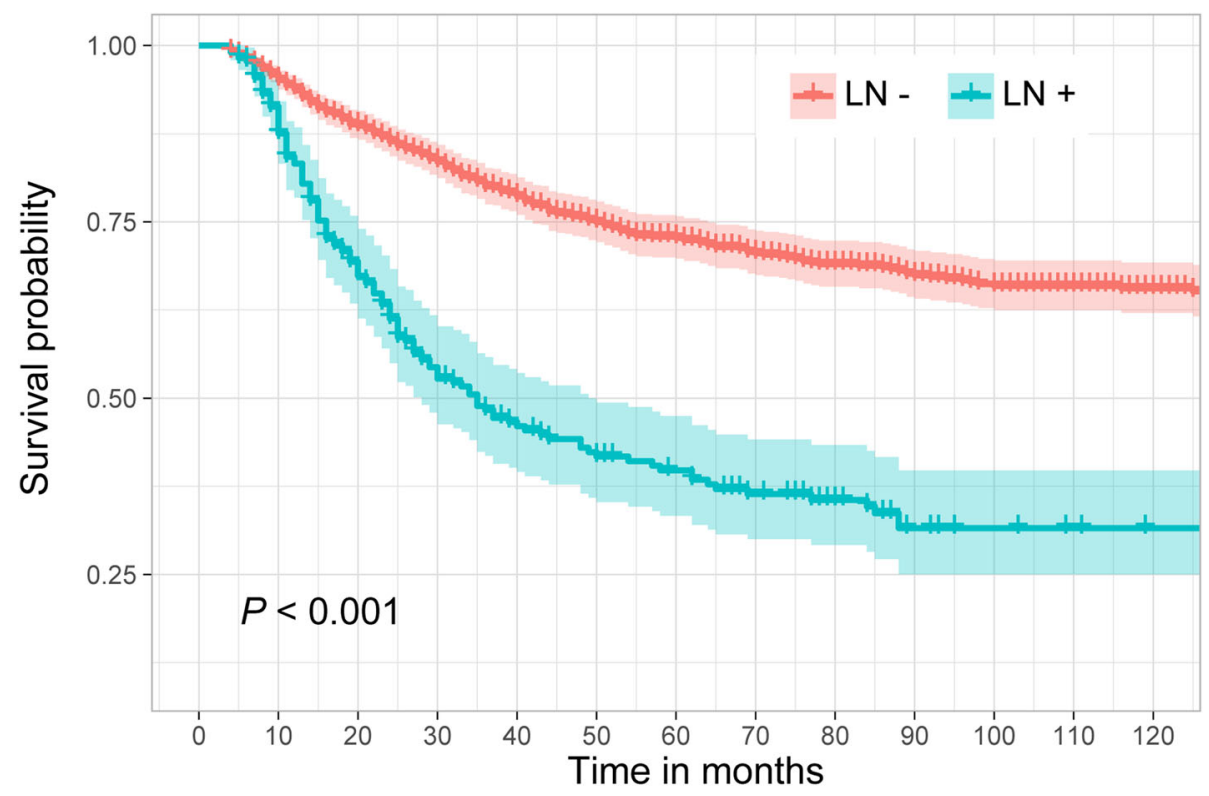

Number at risk

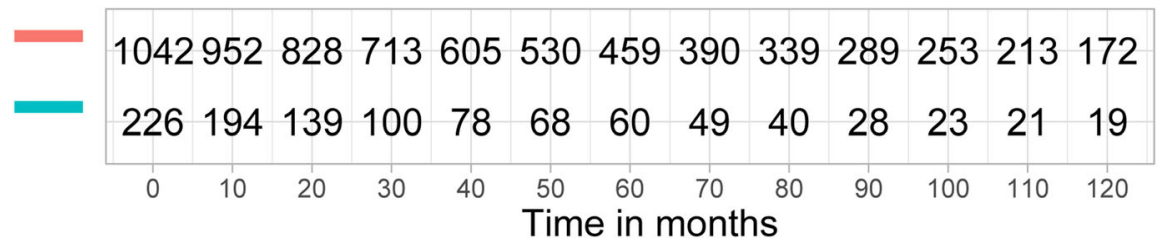

Fig. 2 Esophageal cancer-specific survival curve with and without lymph node metastasis ( $L N+v s L N-)$ 

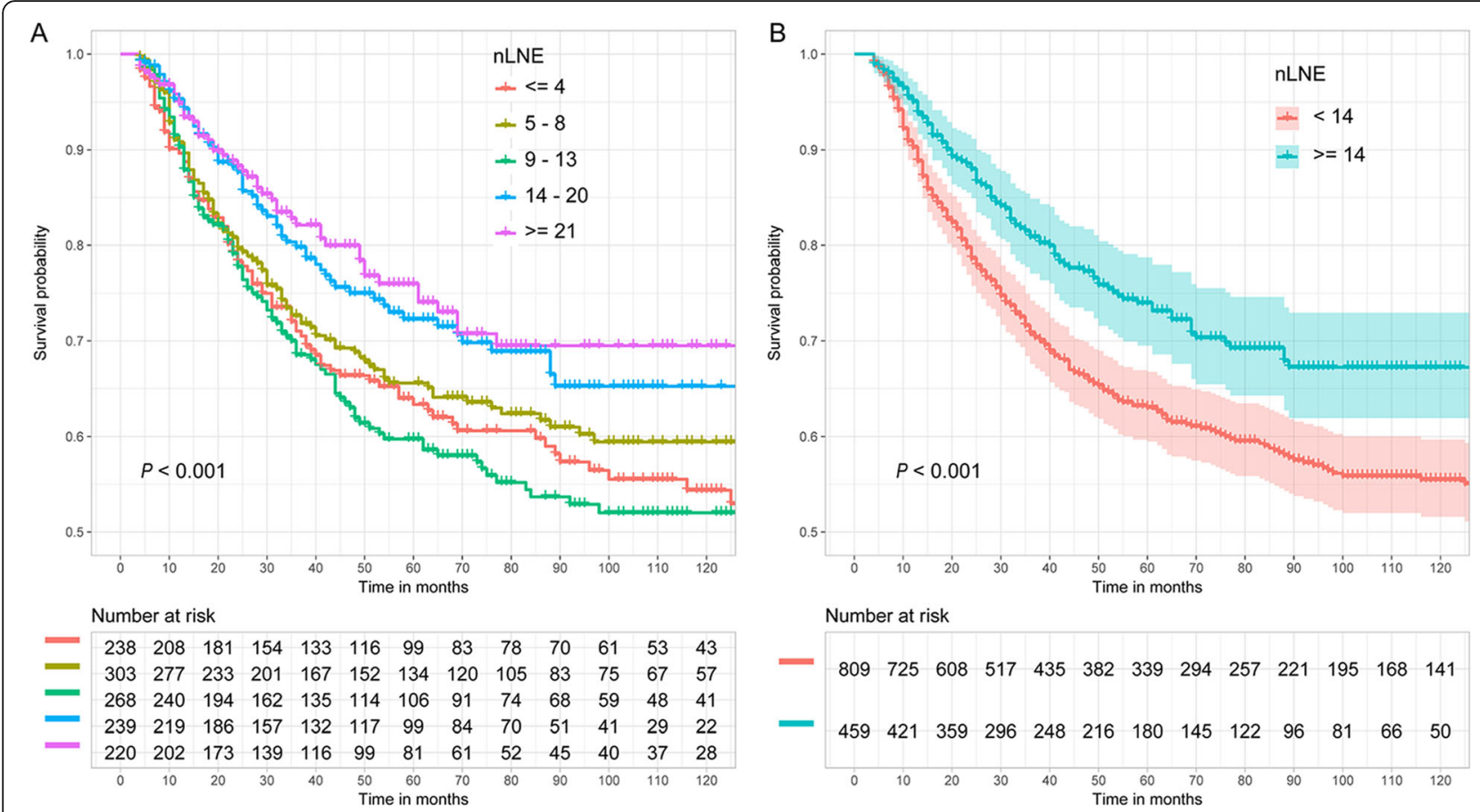

Fig. 3 Esophageal CSS curve for different nLNEs based on two grouping methods. a: $\leq 4,5-8,9-13,14-20$ and $\geq 21 ; \mathbf{b}:<14$ and $\geq 14$

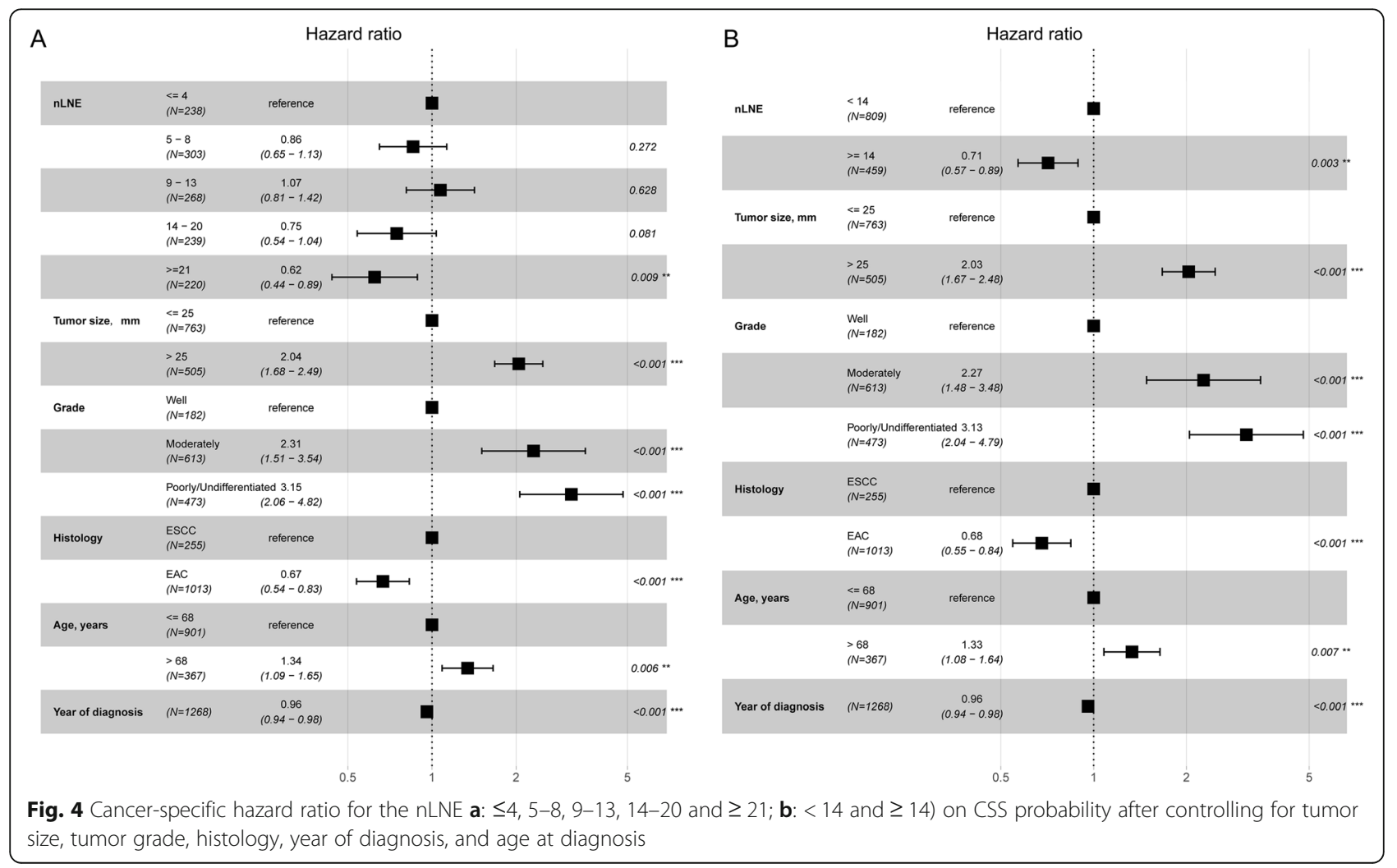



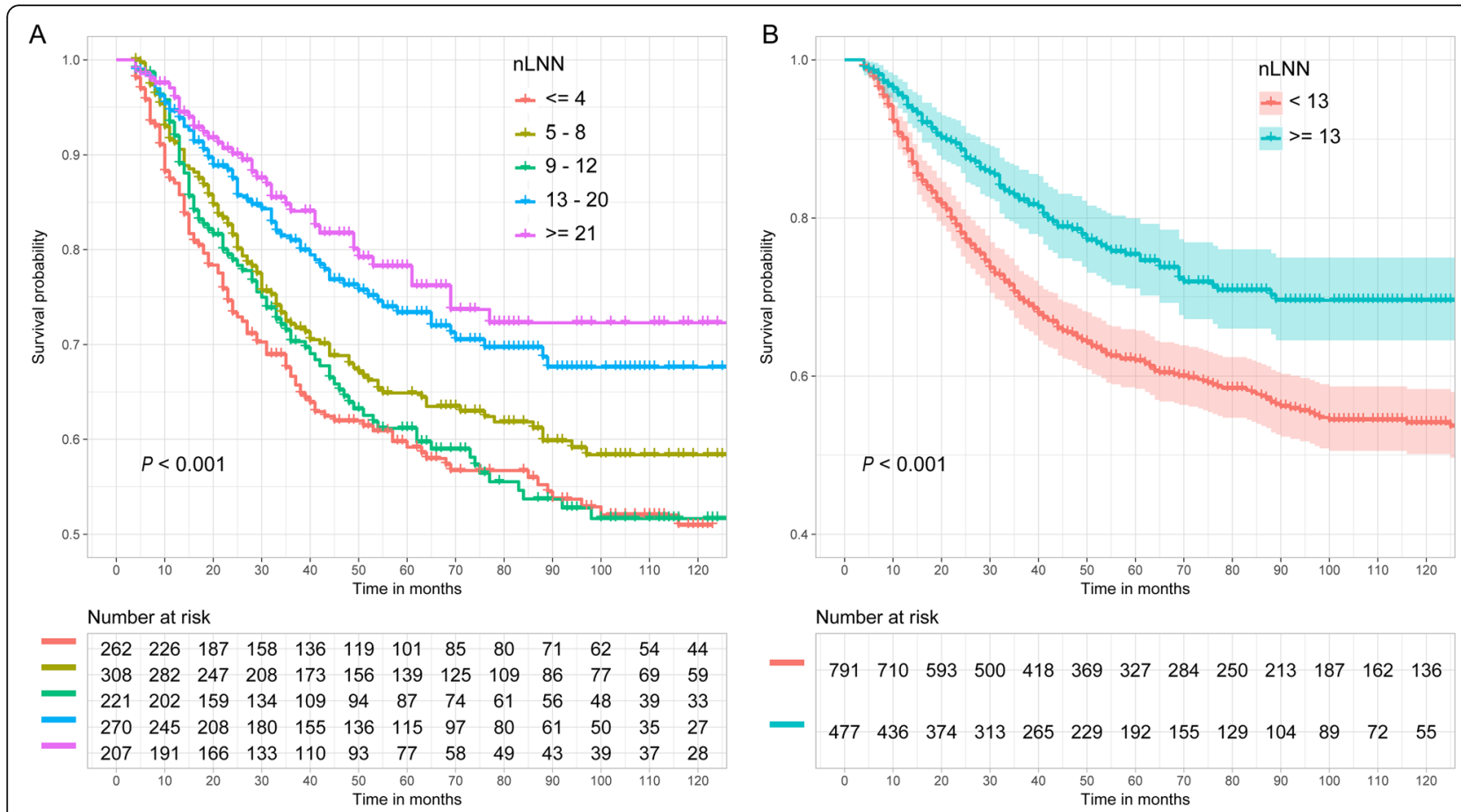

Fig. 5 Esophageal CSS curve for different nLNNs based on the two grouping methods. a: $\leq 4,5-8,9-12,13-20$ and $\geq 21$; b: $<13$ and $\geq 13$
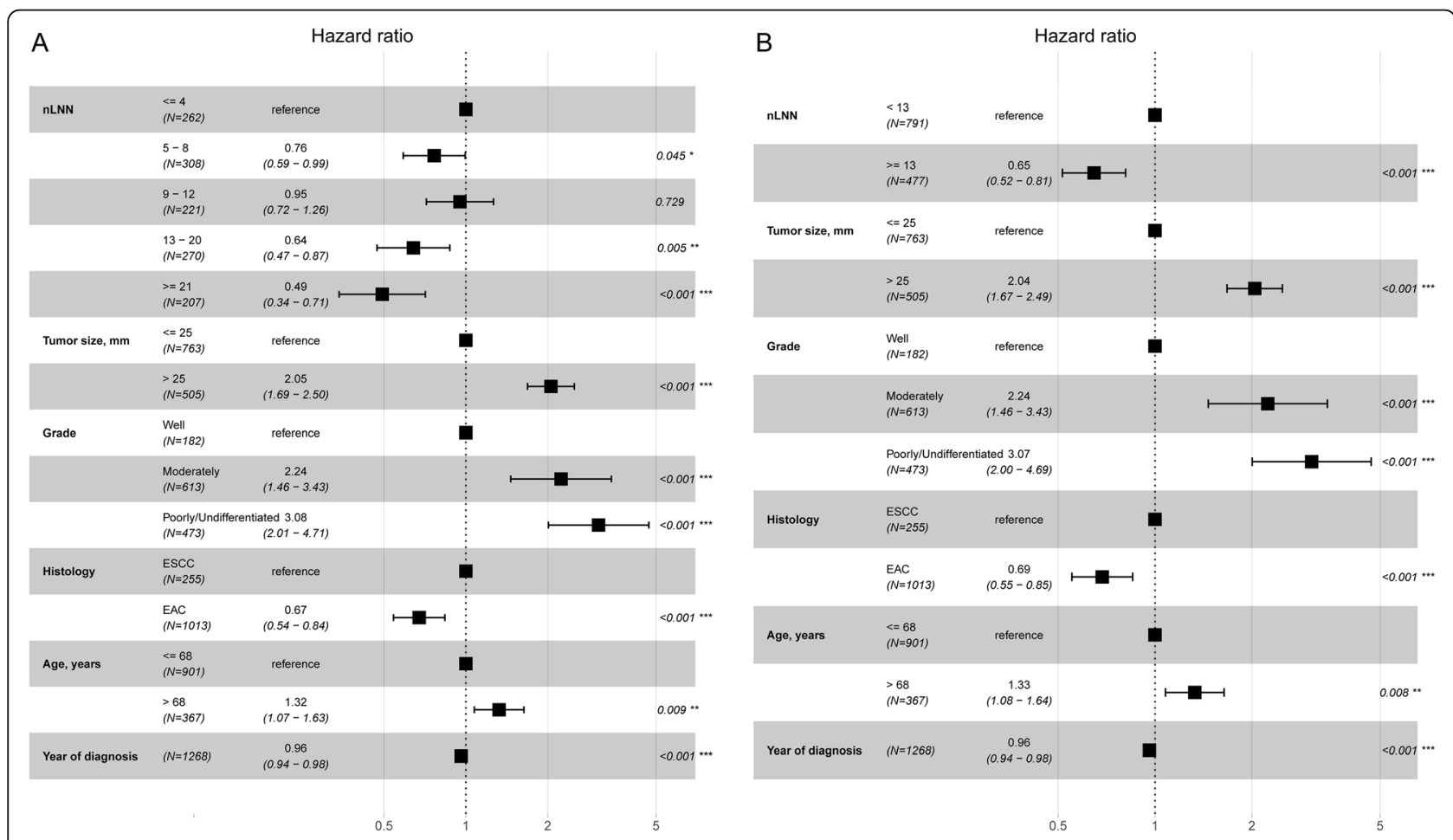

Fig. 6 Cancer-specific HR for the nLNN a: $\leq 4,5-8,9-12,13-20$ and $\geq 21 ; \mathbf{b}:<13$ and $\geq 13$ ) on CSS probability after controlling for tumor size, tumor grade, histology, year of diagnosis, and age at diagnosis 

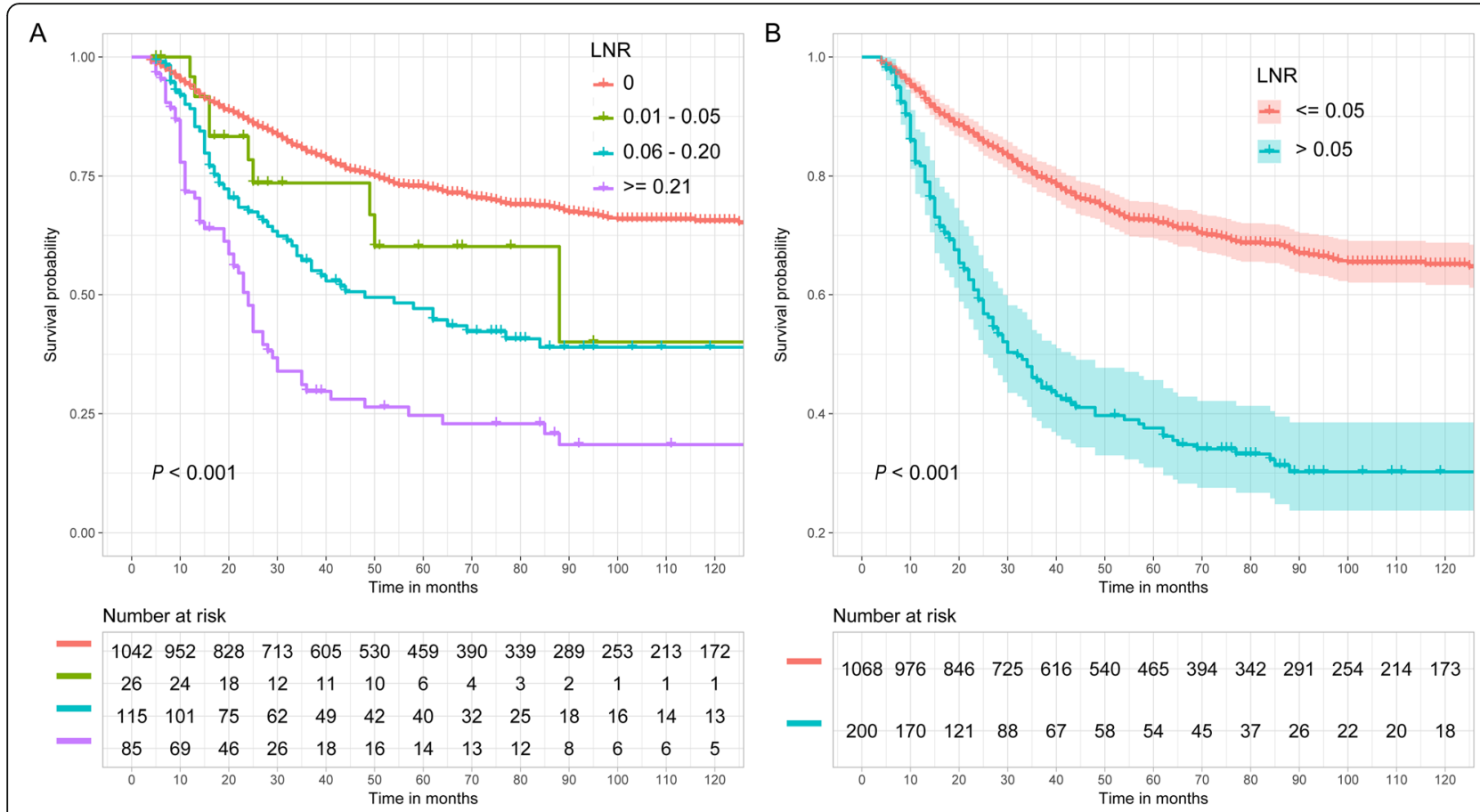

Fig. 7 Esophageal CSS curve for different LNRs based on the two grouping methods. a: $0,0.01-0.05,0.06-0.20$ and $\geq 0.21 ; \mathbf{b}: \leq 0.05$ and $>0.05$

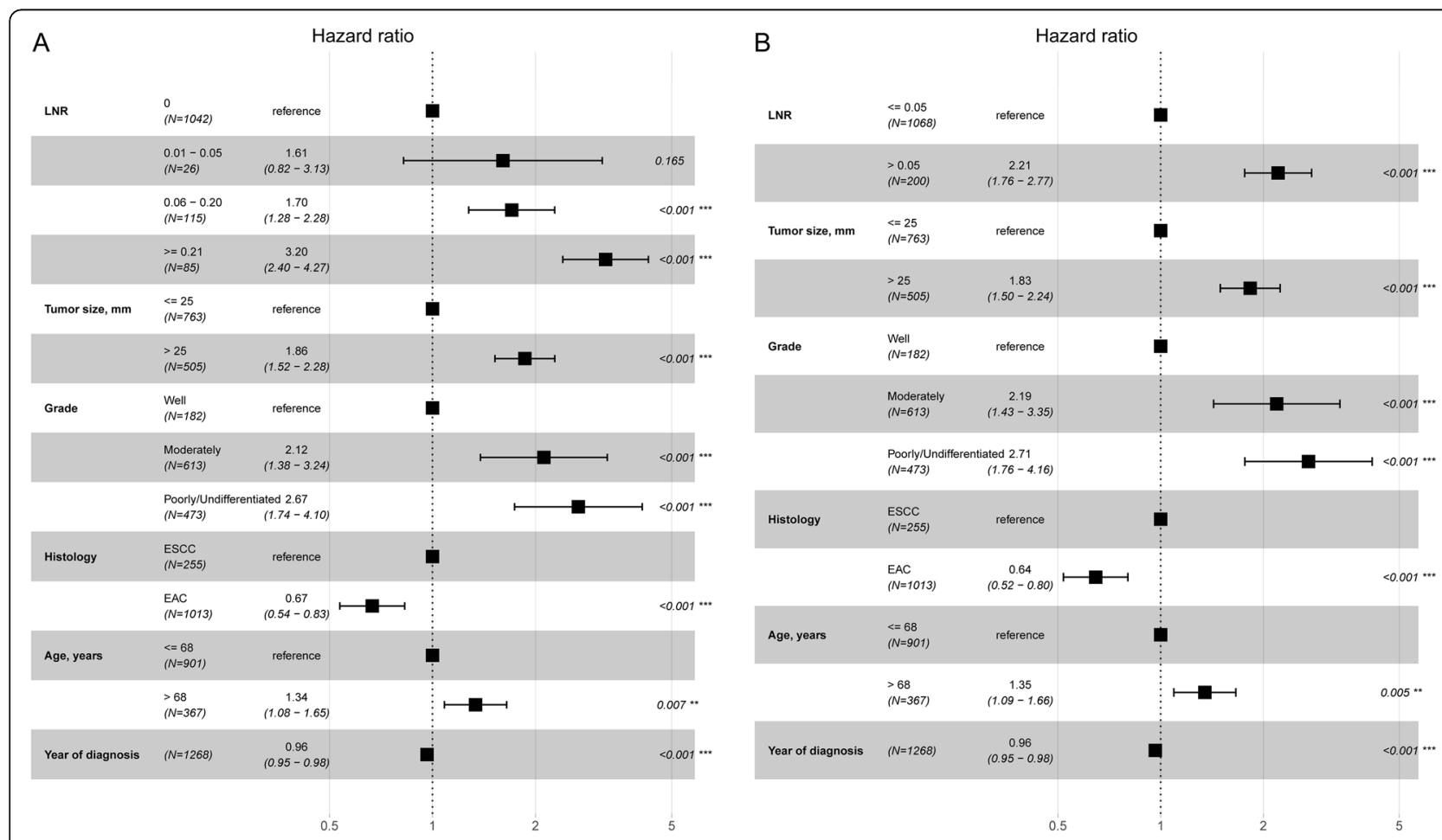

Fig. 8 Cancer-specific HR for the LNR $\mathbf{a}: 0,0.01-0.05,0.06-0.20$ and $\geq 0.21 ; \mathbf{b}$ : $\leq 0.05$ and $>0.05$ ) on CSS probability after controlling for tumor size, tumor grade, histology, year of diagnosis, and age at diagnosis 


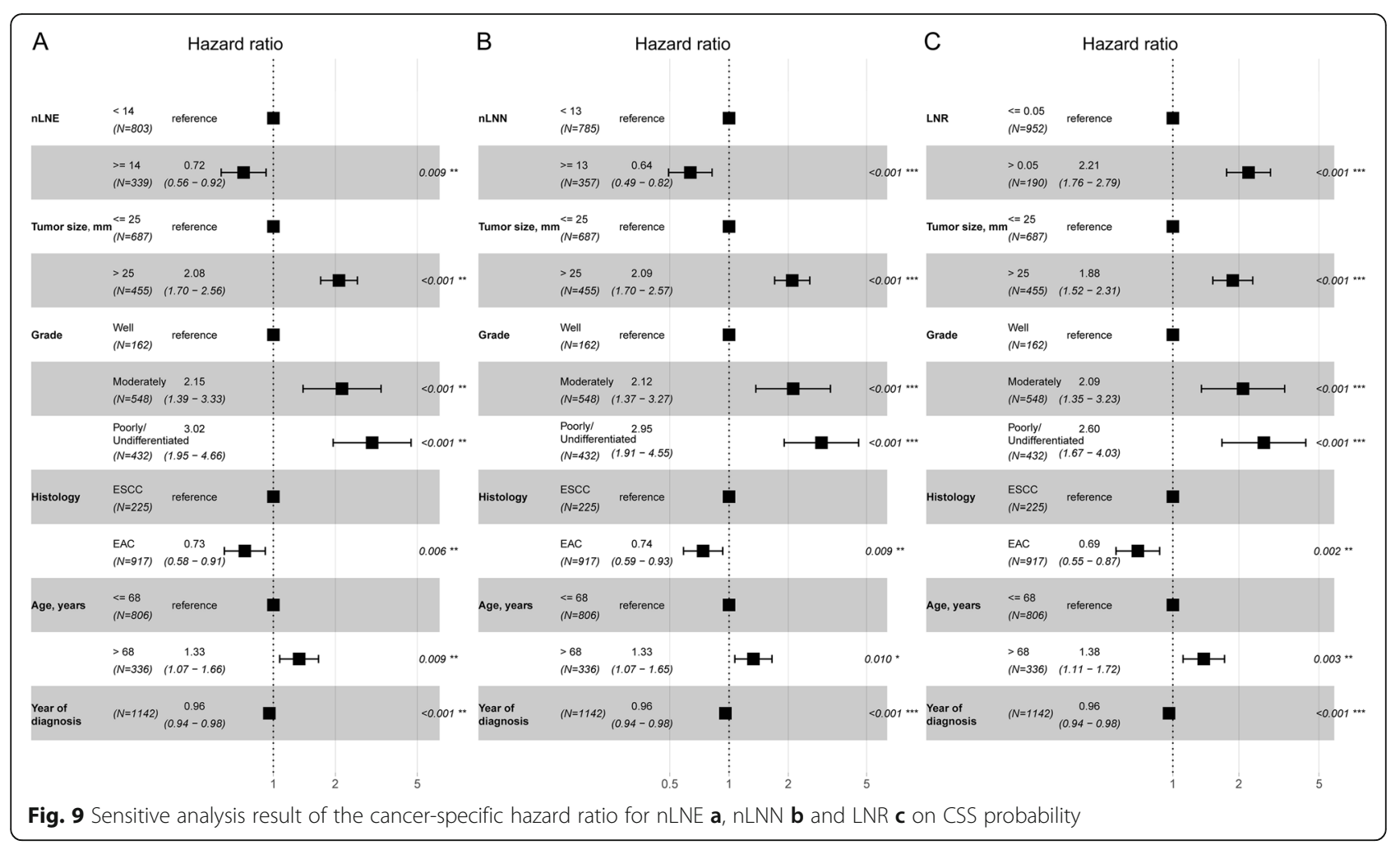

lymph nodes is significantly better than that of patients with $<13$ negative lymph nodes $(P<0.001)$. The estimated 5- and 10-year CSS probabilities for patients with $<13$ negative lymph nodes were 62.0 and $54.1 \%$, respectively, compared with 75.4 and $69.6 \%$ for patients with $\geq 13$ negative lymph nodes.

Figure 6 shows the relationship between nLNN and CSS probability after controlling for other variables, including tumor size, tumor grade, histology, year of diagnosis, and age at diagnosis. Figure 6a corresponds to dividing the nLNN into four groups $(\leq 4,5-8,9-12,13-$ 20 , and $\geq 21$ ), whereas Fig. $6 \mathrm{~b}$ corresponds to dividing the nLNN into two groups $(\geq 13$ and $<13)$. Figure $6 a$ shows that this main variable is statistically associated with CSS probability. The point estimation effects of nLNN among different groups are nonlinear, with the 9-12 group having the largest point estimation, although the difference between the 9-12 group and the $\leq 4$ group is insignificant. Figure $6 \mathrm{~b}$ shows that the cancer-specific death risk of patients with $\mathrm{nLNN} \geq 13$ was decreased by $35 \%$ compared to those with $\mathrm{nLNN}<13$ (HR 0.65, 95\% CI: $0.52-0.81)$.

\section{LNR and esophageal cancer-specific survival}

Figure 7 shows the CSS probability of esophageal cancer for LNR. Figure 7a shows the CSS probability when dividing the patients into four groups $(0,0.01-0.05,0.06-$
0.20 , and $\geq 0.21)$. A significant difference is observed $(P<0.001)$. The larger the LNR is, the smaller the CSS probability. Figure $7 \mathrm{~b}$ shows the CSS probability when dividing the patients into two groups: LNR $\leq 0.05$ and > 0.05 . The CSS probability in the $\leq 0.05$ group was greatly improved compared with that in the $>0.05$ group $(P<$ $0.001)$. The estimated 5- and 10-year CSS probabilities for patients with LNR $\leq 0.05$ were 72.4 and $65.1 \%$, respectively, compared with 37.6 and $30.2 \%$ for patients with LNR $>0.05$.

Figure 8 shows the prognostic value of the LNR for CSS probability after controlling for tumor size, tumor grade, histology, year of diagnosis, and age at diagnosis. Figure $8 \mathrm{a}$ shows that the CSS probability in the 0 group was significantly different from that in the $0.06-0.20$ and $\geq 0.21$ groups but not significantly different from that in the $0.01-0.05$ group. Figure $8 \mathrm{~b}$ shows that the risk of cancer-specific death increased by 1.21 times (HR 2.21 , 95\% CI: $1.76-2.77)$ in the $>0.05$ group compared to the $\leq 0.05$ group.

\section{Sensitivity analysis}

The sensitivity analysis shows that the optimal cutoff points are not affected by excluding patients with extreme tumor size and nLNE values. The effect sizes of nLNE, nLNN and LNR on CSS are almost unchanged as shown in Fig. 9. 


\section{Discussion}

The study evaluated the effect of the extent of lymphadenectomy in T1 patients treated with esophagectomy. The esophageal cancer-specific survival (CSS) probability of patients in stage $\mathrm{T} 1$ is much improved with extensive lymphadenectomy. Our study evaluated three different variables, the number of lymph nodes examined, the number of negative lymph nodes and the LNR, to reveal the prognostic value of the extent of lymphadenectomy. We find that the thresholds of these three variables are 13, 12 and 0.05 . The prognosis of patients was greatly improved in the groups with $\mathrm{nLNE} \geq 14, \mathrm{nLNN} \geq 13$, or LNR $\leq 0.05$ compared to the other groups.

The 5-year survival probability in patients with advanced esophageal cancer can be less than $30 \%$, but the prognosis of patients in the early stage is greatly improved [12,13]. Lymph node metastasis is vital to the prognosis of patients in the early stage. Our study indicated that the CSS probability between patients with and without lymph node metastasis was markedly different in T1 patients. The CSS probability of patients without lymph node metastasis was approximately two times that of patients with lymph node metastasis.

However, lymphatic dissemination is chaotic and unpredictable, and occurs early in tumorigenesis. Because of the abundant lymph-capillary plexus in the lamina propria mucosa and submucosa of the esophagus, the potential for lymph node metastasis exists, even in patients with intramucosal cancer (T1a) [14, 15].
Therefore, a key step in the treatment of T1 patients is to identify metastatic lymph nodes during preoperative diagnosis. However, preoperative identification of patients with lymph node metastasis using the present modalities has many limitations. Thus, esophagectomy with lymphadenectomy is considered the first curative option for early-stage patients.

Most agree that lymphadenectomy does provide the benefit of accurate pathologic staging, but its effect on improving survival is debated. One study using data from the National Cancer Data Base (NCDB) found that examining an increased number of lymph nodes was associated with further survival improvements and recommended that 20 to 25 lymph nodes should be examined [8]. Another international multicenter study showed that the number of lymph nodes removed was an independent predictor of survival, and indicated a minimum of 23 lymph nodes to be removed to maximize the outcome of survival [9]. The study using the SEER database recommended that at least 30 lymph nodes should be removed to maximize survival [16]. One study indicated that the optimum lymphadenectomy was modulated by $\mathrm{T}$ stage. A study using Worldwide Esophageal Cancer Collaboration data recommended that the optimum lymphadenectomy was 10 lymph nodes for T1, 20 for $\mathrm{T} 2$, and $\geq 30$ for T3/T4 [17]. However, some studies have indicated opposite conclusions on the prognostic value of the extent of lymph node excision. Lagergren et al. found that the extent of lymphadenectomy was not statistically
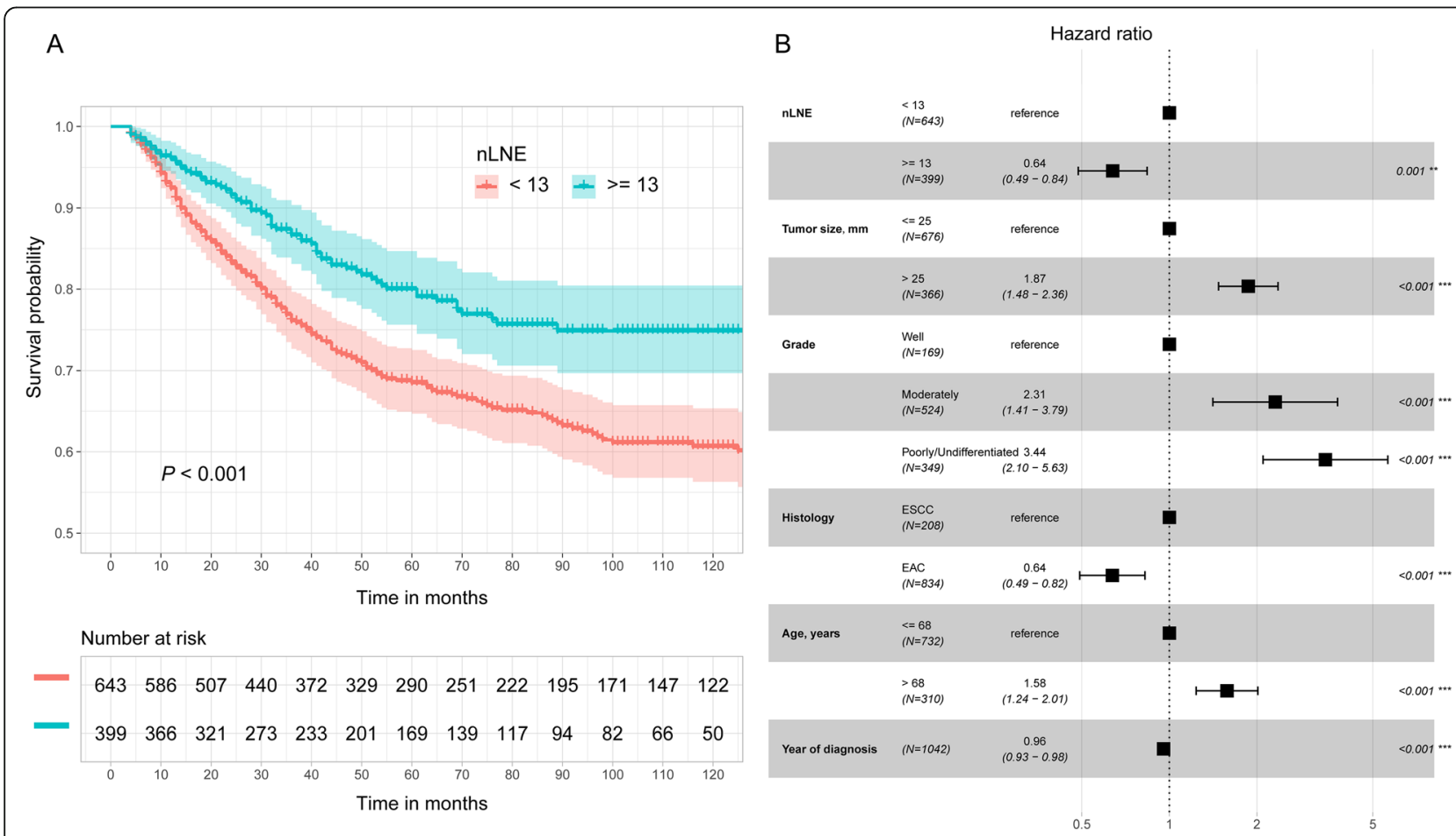

Fig. 10 Esophageal CSS curve $\mathbf{a}$ and effect $\mathbf{b}$ of different lymph node resections in patients without lymph node metastasis 
associated with all-cause or cancer-specific mortality, and the results were the same after stratification by $\mathrm{T}$ category [7]. A Swedish nationwide population-based cohort study also provided evidence that more extensive lymphadenectomy did not improve survival after surgery and might even hamper survival in early $\mathrm{T}$ stage patients [10]; however, it should be noted that the median number of lymph nodes removed in the Swedish study was seven, which is relatively low and cannot effectively identify positive lymph nodes. Based on the controversial results, a recent meta-analysis confirmed that increased lymph node resection was associated with improved overall and cancer-free survival [18].

Similar to the relationship between nLNE and survival, some studies indicated that a higher number of negative lymph nodes was associated with better overall survival [19-21]. Schwarz et al. found that $\geq 15$ negative lymph nodes was associated with the best overall survival [20]. Liu et al. suggested that at least 16 negative lymph nodes should be resected [22]. Yang et al. and Greenstein et al. recommended a minimum resection of 18 negative lymph nodes [21, 23]. We also found that the extent of lymphadenectomy was an independent factor and that improved survival was related to increasing nLNN. This agrees with some population-based studies that confirmed the relationship between the extent of lymphadenectomy and esophageal cancer survival. We further suggest a minimum lymph node dissection of 13 for nLNN for T1 stage patients.

There are two possible explanations for our finding. One is improved survival due to stage migration [24]. As nLNE or nLNN increases, the probability of missing a positive lymph node and erroneously classifying as an earlier stage of cancer decreases. A second explanation is that the number of negative lymph nodes may contribute to a reduction in unrecognized tumor cells. Micrometastases have been shown to be present in up to $56 \%$ of N0 (with no positive lymph nodes examined) patients [25] and can even be up to $15 \%$ in early esophageal cancer [26]. In addition, studies have shown that micrometastases in esophageal cancer are associated with reduced survival and an increased risk of disease recurrence [26, 27]. For patients without lymph node metastasis, our study showed that the CSS probability with $\geq 13$ lymph nodes dissected was much better than that with $<13$ lymph nodes dissected (the estimated 5- and 10 -year CSS probabilities for the $\geq 13$ group vs $<13$ group were $80.0 \%$ vs 68.5 and $74.9 \%$ vs $60.6 \%, P<0.001$ (Fig. 10a)). This corresponded to a $36 \%$ decrease in the risk of cancer-specific death in the group with $\geq 13$ negative lymph nodes compared to the group with $<13$ negative lymph nodes (Fig. 10b). This is consistent with some published studies indicating that high nLNN resection was independently associated with high disease-specific survival in patients with N0 esophageal cancer [22, 23]. The most likely explanation for the observed association between an increasing number of negative lymph node resections and improved survival is the clearance of micrometastasis foci. The current modalities have difficulty identifying small micrometastatic foci. Therefore, extensive lymphadenectomy may improve the prognosis by resecting residual cancer cells. In addition to absolute nLNE and nLNN, some studies also indicated that the LNR was an independent predictor of prognosis: the higher the LNR was, the worse the survival $[7,8,28-31]$. Other studies suggested that LNR $<0.1$ or $<0.2$ was associated with maximum survival benefit $[8,31]$.

Inconsistency exists regarding the cutoff values recommended by these earlier studies. One possibility is that the patients among different studies are heterogeneous. Some studies were based on EAC predominant populations $[9,16,17,23]$, and some were based on ESCC [19, $21,22,32-34]$. Some included early-stage cancer [15, 23, 33 , and others included T1-T4 but mainly advancedstage cancer $[8,9,16,19-21,32]$. The other possibility is the heterogeneity of the method in grouping. Most studies grouped patients based on an arbitrarily defined cutoff points, such as quartiles, which is a subjective method $[7,19,35,36]$. It is difficult to find the real effect of continuous variables. Relatively few studies have used more objective statistical methods to explore the relationship between the extent of lymph node excision and survival $[8,9,17,32]$.

In this study, we explored the relationship between the extent of lymph node resection (including nLNE, nLNN and LNR) and long-term CSS in T1 patients after esophagectomy and lymphadenectomy. It should be noted that surgeons cannot determine nLNN or LNR during the surgery; it can only be done by the pathological department after the surgery. Therefore, the nLNN and LNR indices have scientific value but cannot yet guide practice; however, nLNE can.

We used a large sample size to investigate the association between the extent of lymphadenectomy and cancer-specific death. This is advantageous for detecting any relatively moderate association. Cancer-specific death as the end point event can avoid unrelated causes of death, such as age-related death. There were many non-cancer-related deaths in $\mathrm{T} 1$ patients in our study (cancer-specific deaths vs all-cause deaths: 415 vs 595). Choosing cancer-specific death as the end point can reveal the true effect of the extent of lymph node resection on survival. The populations in our study were all $\mathrm{T} 1$ patients, which is homogenous. Therefore, the conclusion is specific to T1 patients.

This study has its limitations. First, the current AJCC TNM classification separates T1 patients into T1a and T1b based on the distinguished prognosis, but the 
information on tumor infiltration depth in the SEER database classify some patients into $\mathrm{T} 1$, but not specific into T1a and T1b. Second, there is no detailed and clear information regarding resection margin, comorbidity, surgical volume, surgical approach (open versus minimally invasive), surgical technique (Ivor-Lewis versus transhiatal esophagectomy or 2-field versus 3-field lymphadenectomy) and neoadjuvant chemotherapy and radiotherapy. However, neoadjuvant chemotherapy and radiotherapy are not the standard therapies for earlystage cancer, especially for the patients in our study with N0 disease, which accounted for $82.2 \%$. Third, surgeons usually perform lymph nodes dissection according to the histology (EAC and ESCC) and tumor location (cervical, thoracic and abdominal). In our analysis, the ideal case would be to conduct subgroup analyses considering histology and tumor location. However, this would require a larger sample size than what we have in order to achieve the statistical power for a meaningful result. This may be a future study when large enough sample size becomes available. Therefore, readers should view the result of this study as a scientific progress report, not a golden standard for guiding the surgeons, such as 14 as the recommended minimum number of lymph nodes that need to be removed. Furthermore, our study is a retrospective observational study. The results should be verified by conducting a prospective study.

\section{Conclusions}

In summary, the prognosis of early esophageal cancer has largely improved compared to that of advanced cancer. Greater extensive lymphadenectomy can improve cancer-specific survival in T1 patients. This study finds statistically that the minimum number of lymph nodes that need to be removed is 14 . The number of negative lymph nodes and the lymph node ratio also have prognostic value after lymphadenectomy among $\mathrm{T} 1$ stage patients. This study adds to the evidence knowledge pool for improving cancer-specific survival in patients with $\mathrm{T} 1$ esophageal cancer. As future available sample size increases, the accuracy from statistical modelling will also be improved. Therefore, the exact number of lymph node dissection in practices should still be determined based on the guidance from each country, such as tumor location and histology.

\footnotetext{
Abbreviations

AJCC: The American Joint Committee on Cancer; TNM: Tumor Node Metastasis; NCCN: National Comprehensive Cancer Network; nLNE: Number of lymph nodes examined; nLNN: Number of negative lymph nodes; LNR: Lymph node ratio; CSS: Cancer-specific survival; SEER: Surveillance, Epidemiology and End Results; EAC: Esophageal adenocarcinoma; ESCC: Esophageal squamous cell carcinoma; HR: Hazard ratio; Cls: Confidence intervals; NCDB: National Cancer Data Base
}

\section{Authors' contributions}

Conceptualization: YW, XW Z, SW S; Data curation: YW, XW Z, XF Z, LZ, WX KK L; Formal analysis: YW, XF Z JL-H; Funding acquisition: XW Z, YZ J, LZ, SW S; Supervision: SW S, JL-H; Writing - original draft and editing: YW, XW Z, XF Z, JL-H, LZ, WX, YZ J, KK L, SW S; Writing - review \& editing: SW S, JL-H. The authors read and approved the final manuscript.

\section{Funding}

The work was supported by China Postdoctoral Science Foundation (grant number 2018 M630790), and Provincial Science and Technology Development Plan of Shandong (grant number 2016GSF201107), and Clinical Medicine Technology and Innovations Plan of Jinan City (grant numbers 201805070, 201907066). The funding body have no role in the design of the study and collection, analysis, and interpretation of data and in writing the manuscript.

\section{Availability of data and materials}

The datasets generated and/or analysed during the current study are available in the Surveillance, Epidemiology and End Results (SEER) Program databases (https://seer.cancer.gov/data/).

\section{Declarations}

\section{Ethics approval and consent to participate}

Since the SEER data are de-identified and publicly available. Therefore, the study is exempted from institutional ethical board review.

\section{Consent for publication}

Not applicable.

\section{Competing interests}

The authors declare that they have no competing interests.

\section{Author details}

${ }^{1}$ Department of Medical Imaging, Shandong Provincial Hospital Affiliated to Shandong First Medical University, Jinan 250021, People's Republic of China. ${ }^{2}$ Department of Thoracic Surgery, Shandong Provincial Hospital Affiliated to Shandong First Medical University, Jinan 250021, People's Republic of China. ${ }^{3}$ Department of Respiratory and Critical care, Shandong Public Health Clinical Center, Jinan 250013, People's Republic of China. ${ }^{4}$ Centre for Sami Research, Umea University, SE-901 85 Umea, Sweden. ${ }^{5}$ Shandong Institute of Clinical Medicine, Shandong Provincial Hospital Affiliated to Shandong First Medical University, Jinan 250021, People's Republic of China. ${ }^{6}$ Clinical Epidemiology Unit, Qilu Hospital of Shandong University, 107 Wenhua Road, Lixia District, Jinan 250012, People's Republic of China. ${ }^{7}$ Clinical Research Center of Shandong University, Jinan 250012, People's Republic of China. ${ }^{8}$ Department of Epidemiology and Health Statistics, School of Public Health, Shandong University, Jinan, Shandong, People's Republic of China.

Received: 10 November 2020 Accepted: 22 March 2021

Published online: 14 April 2021

References

1. Ajani JA, D'Amico TA, Bentrem DJ, Chao J, Corvera C, Das P, et al. Esophageal and Esophagogastric junction cancers, version 2.2019, NCCN clinical practice guidelines in oncology. J Natl Compr Cancer Netw. 2019; 17(7):855-83. https://doi.org/10.6004/jnccn.2019.0033.

2. Holscher $A H$, Bollschweiler E, Schneider PM, Siewert JR. Prognosis of early esophageal cancer. Comparison between adeno- and squamous cell carcinoma. Cancer. 1995;76(2):178-86. https://doi.org/10.1002/1097-0142 (19950715)76:2<178::AID-CNCR2820760204>3.0.CO;2-D.

3. Stein HJ, Feith M, Bruecher BL, Naehrig J, Sarbia M, Siewert JR. Early esophageal cancer: pattern of lymphatic spread and prognostic factors for long-term survival after surgical resection. Ann Surg. 2005;242(4):566-73; discussion 573-565. https://doi.org/10.1097/01.sla.0000184211.75970.85.

4. Duan XF, Tang P, Shang XB, Jiang HJ, Yu ZT. The prevalence of lymph node metastasis for pathological T1 esophageal cancer: a retrospective study of 143 cases. Surg Oncol. 2018;27(1):1-6. https://doi.org/10.1016/j.suronc.201 7.11.002.

5. Akutsu Y, Uesato M, Shuto K, Kono T, Hoshino I, Horibe D, et al. The overall prevalence of metastasis in $\mathrm{T} 1$ esophageal squamous cell carcinoma: a 
retrospective analysis of 295 patients. Ann Surg. 2013;257(6):1032-8. https:// doi.org/10.1097/SLA.0b013e31827017fc.

6. Akutsu Y, Kato K, Igaki H, Ito Y, Nozaki I, Daiko H, et al. The prevalence of overall and initial lymph node metastases in clinical T1N0 thoracic esophageal Cancer: from the results of JCOG0502, a prospective multicenter study. Ann Surg. 2016;264(6):1009-15. https://doi.org/10.1097/SLA. 0000000000001557.

7. Lagergren J, Mattsson F, Zylstra J, Chang F, Gossage J, Mason R, et al. Extent of lymphadenectomy and prognosis after esophageal Cancer surgery. JAMA Surg. 2016;151(1):32-9. https://doi.org/10.1001/jamasurg.2015.2611.

8. Samson P, Puri V, Broderick S, Patterson GA, Meyers B, Crabtree T. Extent of lymphadenectomy is associated with improved overall survival after Esophagectomy with or without induction therapy. Ann Thorac Surg. 2017; 103(2):406-15. https://doi.org/10.1016/j.athoracsur.2016.08.010.

9. Peyre CG, Hagen JA, DeMeester SR, Altorki NK, Ancona E, Griffin SM, et al. The number of lymph nodes removed predicts survival in esophageal cancer: an international study on the impact of extent of surgical resection. Ann Surg. 2008;248(4):549-56. https://doi.org/10.1097/SLA.0b013e318188c4 74.

10. van der Schaaf M, Johar A, Wijnhoven B, Lagergren P, Lagergren J. Extent of lymph node removal during esophageal cancer surgery and survival. J Natl Cancer Inst. 2015;107:5.

11. Hothorn T, Lausen B. On the exact distribution of maximally selected rank statistics. Comput Stat Data Anal. 2003;3(2):121-37.

12. Grotenhuis BA, van Heijl M, Zehetner J, Moons J, Wijnhoven BP, van Berge Henegouwen Ml, et al. Surgical management of submucosal esophageal cancer: extended or regional lymphadenectomy? Ann Surg. 2010;252(5): 823-30. https://doi.org/10.1097/SLA.0b013e3181fcd730.

13. Tanaka T, Matono S, Nagano T, Shirouzu K, Fujita H, Yamana H. Esophagectomy with extended lymphadenectomy for submucosal esophageal cancer: long-term outcomes and prognostic factors. Ann Surg Oncol. 2012;19(3):750-6. https://doi.org/10.1245/s10434-011-2023-6.

14. Leers JM, DeMeester SR, Oezcelik A, Klipfel N, Ayazi S, Abate E, et al. The prevalence of lymph node metastases in patients with $\mathrm{T1}$ esophageal adenocarcinoma a retrospective review of esophagectomy specimens. Ann Surg. 2011;253(2):271-8. https://doi.org/10.1097/SLA.0b013e3181fbad42.

15. Liu L, Hofstetter WL, Rashid A, Swisher SG, Correa AM, Ajani JA, et al. Significance of the depth of tumor invasion and lymph node metastasis in superficially invasive (T1) esophageal adenocarcinoma. Am J Surg Pathol. 2005;29(8):1079-85.

16. Groth SS, Virnig BA, Whitson BA, DeFor TE, Li ZZ, Tuttle TM, et al. Determination of the minimum number of lymph nodes to examine to maximize survival in patients with esophageal carcinoma: data from the surveillance epidemiology and end results database. J Thorac Cardiovasc Surg. 2010;139(3):612-20. https://doi.org/10.1016/j.jtcvs.2009.07.017.

17. Rizk NP, Ishwaran H, Rice TW, Chen LQ, Schipper PH, Kesler KA, et al. Optimum lymphadenectomy for esophageal cancer. Ann Surg. 2010;251(1): 46-50. https://doi.org/10.1097/SLA.0b013e3181b2f6ee.

18. Visser E, Markar SR, Ruurda JP, Hanna GB, van Hillegersberg R. Prognostic value of lymph node yield on overall survival in esophageal Cancer patients: a systematic review and meta-analysis. Ann Surg. 2019;269(2):261-8. https:// doi.org/10.1097/SLA.0000000000002824.

19. Hsu PK, Huang CS, Wang BY, Wu YC, Chou TY, Hsu WH. The prognostic value of the number of negative lymph nodes in esophageal cancer patients after transthoracic resection. Ann Thorac Surg. 2013;96(3):995-1001. https://doi.org/10.1016/j.athoracsur.2013.04.098.

20. Schwarz RE, Smith DD: Clinical impact of lymphadenectomy extent in resectable esophageal cancer. J Gastrointest Surg 2007, 11(11):1384-1393; discussion 1393-1384, DOl: https://doi.org/10.1007/s11605-007-0264-2.

21. Yang HX, Xu Y, Fu JH, Wang JY, Lin P, Rong TH. An evaluation of the number of lymph nodes examined and survival for node-negative esophageal carcinoma: data from China. Ann Surg Oncol. 2010;17(7):190111. https://doi.org/10.1245/s10434-010-0948-9.

22. Liu Q, Tan Z, Lin P, Long H, Zhang L, Rong T, et al. Impact of the number of resected lymph nodes on postoperative survival of patients with nodenegative oesophageal squamous cell carcinoma. Eur J Cardiothorac Surg. 2013;44(4):631-6. https://doi.org/10.1093/ejcts/ezt097.

23. Greenstein AJ, Litle VR, Swanson SJ, Divino CM, Packer S, Wisnivesky JP. Effect of the number of lymph nodes sampled on postoperative survival of lymph node-negative esophageal cancer. Cancer. 2008;112(6):1239-46. https://doi.org/10.1002/cncr.23309.
24. Hulscher JB, Van Sandick JW, Offerhaus GJ, Tilanus HW, Obertop H, Van Lanschot JJ. Prospective analysis of the diagnostic yield of extended en bloc resection for adenocarcinoma of the oesophagus or gastric cardia. Br J Surg. 2001;88(5):715-9. https://doi.org/10.1046/.1365-2168.2001.01746.x.

25. Hosch S, Kraus J, Scheunemann P, Izbicki JR, Schneider C, Schumacher U, et al. Malignant potential and cytogenetic characteristics of occult disseminated tumor cells in esophageal cancer. Cancer Res. 2000;60(24): 6836-40.

26. Prenzel KL, Holscher AH, Drebber U, Agavonova M, Gutschow CA, Bollschweiler E. Prognostic impact of nodal micrometastasis in early esophageal cancer. Eur J Surg Oncol. 2012;38(4):314-8. https://doi.org/10.1 016/j.ejso.2012.01.007.

27. Izbicki JR, Hosch SB, Pichlmeier U, Rehders A, Busch C, Niendorf A, et al. Prognostic value of immunohistochemically identifiable tumor cells in lymph nodes of patients with completely resected esophageal cancer. N Engl J Med. 1997;337(17):1 188-94. https://doi.org/10.1056/NEJM1997102333 71702.

28. Kelty CJ, Kennedy CW, Falk GL. Ratio of metastatic lymph nodes to total number of nodes resected is prognostic for survival in esophageal carcinoma. J Thorac Oncol. 2010;5(9):1467-71. https://doi.org/10.1097/JTO. ob013e3181e8f6b1.

29. Hsu WH, Hsu PK, Hsieh CC, Huang CS, Wu YC. The metastatic lymph node number and ratio are independent prognostic factors in esophageal cancer. J Gastrointest Surg. 2009;13(11):1913-20. https://doi.org/10.1007/s11605-0090982-8.

30. Greenstein AJ, Litle VR, Swanson SJ, Divino CM, Packer S, Wisnivesky JP. Prognostic significance of the number of lymph node metastases in esophageal cancer. J Am Coll Surg. 2008;206(2):239-46. https://doi.org/10.1 016/j.jamcollsurg.2007.09.003.

31. Tan Z, Ma G, Yang H, Zhang L, Rong T, Lin P. Can lymph node ratio replace pn categories in the tumor-node-metastasis classification system for esophageal cancer? J Thorac Oncol. 2014;9(8):1214-21. https://doi.org/10.1 097/JTO.00000000000000216.

32. Ho HJ, Chen HS, Hung WH, Hsu PK, Wu SC, Chen HC, et al. Survival impact of Total resected lymph nodes in esophageal Cancer patients with and without Neoadjuvant Chemoradiation. Ann Surg Oncol. 2018;25(13):382032. https://doi.org/10.1245/s10434-018-6785-y.

33. Park SY, Kim DJ, Son T, Lee YC, Lee CY, Lee JG, et al. Extent of Mediastinal lymphadenectomy and survival in superficial esophageal squamous cell carcinoma. J Gastrointest Surg. 2017;21 (10):1584-90. https://doi.org/10.1007/ s11605-017-3471-5.

34. Hu Y, Hu C, Zhang H, Ping Y, Chen LQ. How does the number of resected lymph nodes influence TNM staging and prognosis for esophageal carcinoma? Ann Surg Oncol. 2010;17(3):784-90. https://doi.org/10.1245/s1 0434-009-0818-5.

35. Altorki NK, Zhou XK, Stiles B, Port JL, Paul S, Lee PC, et al. Total number of resected lymph nodes predicts survival in esophageal cancer. Ann Surg. 2008;248(2):221-6. https://doi.org/10.1097/SLA.0b013e31817bbe59.

36. Phillips AW, Lagarde SM, Navidi M, Disep B, Griffin SM. Impact of extent of lymphadenectomy on survival, post Neoadjuvant chemotherapy and transthoracic Esophagectomy. Ann Surg. 2017;265(4):750-6. https://doi.org/1 $0.1097 /$ SLA.0000000000001737.

\section{Publisher's Note}

Springer Nature remains neutral with regard to jurisdictional claims in published maps and institutional affiliations.

\section{Ready to submit your research? Choose BMC and benefit from:}

- fast, convenient online submission

- thorough peer review by experienced researchers in your field

- rapid publication on acceptance

- support for research data, including large and complex data types

- gold Open Access which fosters wider collaboration and increased citations

- maximum visibility for your research: over $100 \mathrm{M}$ website views per year

At BMC, research is always in progress.

Learn more biomedcentral.com/submissions 